Revista Brasileira de Agricultura Irrigada v.13, no .4, p. 3599 - 3609, 2019

ISSN 1982-7679 (On-line)

Fortaleza, CE, INOVAGRI - http://www.inovagri.org.br

DOI: $10.7127 /$ rbai.v13n4001091

Protocolo 1091.19 - 24/05/2019 Aprovado em 11/12/2019

\title{
TROCAS GASOSAS EM CULTIVARES DE ALFACE CRESPA EM CULTIVO HIDROPÔNICO COM ÁGUA SALINA
}

\author{
Rafaela Félix Basílio Guimarães ${ }^{1}$, Sebastião de Oliveira Maia Júnior ${ }^{2}$, Ronaldo do Nascimento ${ }^{3}$, \\ Daniele Ferreira de Melo ${ }^{1}$, Jailton Garcia Ramos ${ }^{1}$, Jailma Ribeiro de Andrade ${ }^{4}$
}

\section{RESUMO}

O cultivo hidropônico de hortaliças tem se destacado como uma técnica promissora no cultivo de espécies de ciclo curto, como a alface. Este estudo teve como objetivo avaliar as trocas gasosas de duas cultivares de alface crespa cultivada em hidroponia sob diferentes níveis de condutividade elétrica da solução nutritiva. O experimento foi realizado em ambiente protegido na Universidade Federal de Campina Grande (UFCG), Campus I, em delineamento experimental inteiramente casualizado e esquema fatorial $4 \times 2$, sendo quatro níveis da condutividade elétrica da solução nutritiva: 1,$6 ; 3,6 ; 5,6$ e 7,6 dS m$~^{-1}$, e duas cultivares de alface crespa: Valentina e Alcione, totalizando 8 tratamentos com 3 repetições cada. As trocas gasosas foram avaliadas aos 7, 14 e 21 dias após o transplantio. A salinidade aumentou a transpiração e a taxa de fotossíntese líquida aos sete dias e reduziu a partir dos 14 dias após o transplantio, enquanto o contrário ocorreu com a concentração interna de $\mathrm{CO}_{2}$. Ambas as cultivares desempenharam mecanismos de adaptação ao estresse salino durante os sete primeiros dias de exposição em cultivo hidropônico, sendo afetadas a partir dos 14 dias, porém sem sofrer injúrias visuais.

Palavras-chave: condutividade elétrica, Lactuca sativa L., fotossíntese.

\section{LEAF GAS EXCHANGE OF CURLY LETTUCE CULTIVARS IN HYDROPONIC CULTIVATION WITH SALINE WATER}

\footnotetext{
ABSTRACT

${ }^{1}$ Doutorando(a) em Engenharia Agrícola, Universidade Federal de Campina Grande, Campina Grande, Paraíba, Brasil. E-mail: rafaellafelix_@hotmail.com; danielemelo@hotmail.com; jailtonbiossistemas@gmail.com

${ }^{2}$ Pós-doutorando Junior do CNPq, Universidade Federal de Campina Grande, Campina Grande, Paraíba, Brasil. E-mail: juniormaiagrari@hotmail.com

3 Professor Doutor, Universidade Federal de Campina Grande, Campina Grande, Paraíba, Brasil. E-mail: ronaldon453@gmail.com

4 Doutora em Agronomia, Universidade Federal de Alagoas, Rio Largo, Alagoas, Brasil. E-mail: jailma_asf@hotmail.com
} 
The hydroponic cultivation of vegetables has been highlighted as a promising technique in the cultivation of short cycle species, such as lettuce. The objective of this study was to evaluate the leaf gas exchange of two cultivars of curly lettuce cultivated in hydroponics under different levels of electrical conductivity of the nutrient solution. The experiment was carried out in a greenhouse at the Federal University of Campina Grande (UFCG), Campus I, in a completely randomized experimental design and $4 \times 2$ factorial scheme, with four levels of electrical conductivity of the nutrient solution: $1.6 ; 3.6 ; 5.6$ and $7.6 \mathrm{dS} \mathrm{m}^{-1}$, and two cultivars of curly lettuce: Valentina and Alcione, totalizing 8 treatments with 3 repetitions each. The leaf gas exchanges were evaluated at 7 , 14 and 21 days after transplanting. Salinity increased transpiration and net photosynthesis rate at seven days and decreased after 14 days after transplanting, while the opposite occurred with the internal $\mathrm{CO}_{2}$ concentration. Both cultivars underwent mechanisms of adaptation to saline stress during the first seven days of hydroponic culture exposure, being affected from 14 days, but without suffering visual injuries.

Keywords: electrical conductivity, Lactuca sativa L., photosynthesis.

\section{INTRODUÇÃO}

A alface (Lactuca sativa L.) é considerada a hortaliça folhosa mais cultivada e consumida no mundo (ECHER et al., 2016). No Brasil, a área plantada em 2017 foi de aproximadamente 39 mil hectares, ocupando a segunda posição entre as hortaliças produzidas, sendo a variedade crespa a mais cultivada em ordem de importância econômica (SALA; COSTA, 2012). De acordo com Paulus et al. (2012), a alface é uma hortaliça exigente em água, portanto, a quantidade e a qualidade da mesma podem influenciar diretamente na produtividade da cultura.

Neste sentido, a produção de alface em regiões semiáridas acaba sendo limitada ou inviabilizada, tendo em vista que essas regiões apresentam altas temperaturas, e baixos índices pluviométricos distribuídos irregularmente (PAULUS et al., 2012; SALA; COSTA, 2012), além de ter predominância de rochas cristalinas no subsolo, o que impõe características salobras e salinas às águas subterrâneas, que por vezes é a única alternativa de suprimento hídrico para a produção agrícola em diversos locais (BRITO et al., 2016). No entanto, como a alface é considerada uma cultura moderadamente sensível à salinidade (AYERS; WESTCOT, 1999), a utilização de água com altos teores de sais pode provocar efeitos prejudiciais devido a alterações no potencial osmótico, toxicidade iônica ou desequilíbrio nutricional (DIAS; BLANCO, 2010).

Assim, tem-se buscado técnicas alternativas de cultivo, como a hidroponia, possibilitando a utilização de água salina no cultivo da alface sem causar danos fisiológicos às plantas $\mathrm{e}$, consequentemente, redução no rendimento produtivo (PAULUS et al., 2010; GUIMARÃES et al., 2017; SILVA et al., 2018), e deste modo fomentar a produção desta hortaliça em áreas com disponibilidade de água salina.

Pesquisas apontam o cultivo hidropônico com água salina como técnica promissora no cultivo de hortaliças. Em coentro (Coriandrum sativum L.) sob cultivo hidropônico DFT (técnica do fluxo profundo) foi observado que esse pode ser realizado com água salina de até $7,0 \mathrm{dS} \mathrm{m}{ }^{-1}$, com reduções de crescimento e produção, mas sem efeitos deletérios sobre a qualidade visual (SILVA et al., 2018). Semelhante, em alface sob cultivo hidropônico NFT (fluxo laminar de nutrientes) a utilização de água salobra resultou na redução do consumo hídrico das plantas, com o aumento da salinidade da água, sem causar sintomas de deficiência mineral, apesar de diminuir o crescimento das plantas (PAULUS et al., 2012), bem como a produção de folhas frescas até a salinidade de $3,5 \mathrm{dS} \mathrm{m}^{-1}$ (GUIMARÃES et al., 2017). 
Guimarães et al.

Esse comportamento produtivo de plantas de alface como reduções no crescimento e na produção de massa fresca sem causar danos visuais, pode ser compreendido por meio da avaliação das trocas gasosas, o que melhor explicaria os prejuízos fisiológicos causados pela salinidade a essas plantas, bem como a severidade do estresse sem, contudo, danificar as plantas uma vez que se trata de uma análise não destrutiva.

Assim, objetivou-se com esse trabalho avaliar o efeito de diferentes níveis de salinidade da água sobre as trocas gasosas foliares de duas cultivares de alface crespa, cultivadas em sistema hidropônico.

\section{MATERIAIS E MÉTODOS}

O experimento foi desenvolvido na Universidade Federal de Campina Grande (UFCG), situada no município de Campina Grande, PB, sob as coordenadas geográficas

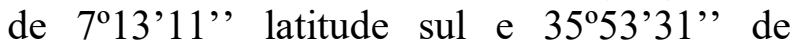
longitude oeste e altitude de $550 \mathrm{~m}$.

$\mathrm{O}$ experimento foi instalado em setembro de 2016, conduzido em casa de vegetação convencional, que possui estrutura em arcos galvanizados, com dimensões de 6,0 $\mathrm{m}$ de largura $\mathrm{x} 10 \mathrm{~m}$ de comprimento e pédireito de 3,0 m, coberta com filme plástico transparente, e laterais envolvidas com telado que permitem a passagem parcial do vento, amenizando a temperatura interna. No interior da casa de vegetação existem quatro bancadas de plantio hidropônico em sistema Nutrient Film Technique (NFT), ou seja, técnica do fluxo laminar de nutrientes, espaçadas $0,80 \mathrm{~m}$, com altura inicial de $1,10 \mathrm{~m}$ e declividade de $2 \%$. Os perfis são espaçados em $0,10 \mathrm{~m} \mathrm{e}$ apresentam comprimento de 4,0 m. Os perfis referentes a cada tratamento são interligados a um reservatório de plástico rígido com capacidade de $300 \mathrm{~L}$, onde se armazenava a solução nutritiva.

A vazão da solução nos canais e a potência da bomba foi determinada considerando a recomendação de Furlani et al. (1999). Cada bomba foi conectada a um temporizador analógico, ligado à rede elétrica, para manter a solução circulando automaticamente. Os temporizadores foram programados para irrigações a cada 15 minutos durante o dia (BLISKA; HONÓRIO, 1996), e intervalos de uma hora durante a noite.

Os tratamentos foram arranjados em esquema fatorial $4 \times 2$, sendo duas cultivares de alface: Valentina (C1) e Alcione (C2) submetidas a quatro níveis de condutividade elétrica da água $\left(1,6 ; 3,6 ; 5,6\right.$ e 7,6 dS m$\left.{ }^{-1}\right)$, totalizando oito tratamentos com 3 repetições (cada repetição foi representada por um perfil ou canal de cultivo, com 12 plantas cada).

As cultivares foram semeadas em espuma fenólica previamente lavada com água corrente, para eliminar possíveis resíduos remanescentes de sua fabricação, sendo o desenvolvimento das mudas ocorrido na estrutura hidropônica da Hortifrut Sempre Verde, localizado no município de Lagoa Seca, PB, onde as placas foram inicialmente umedecidas somente com água de chuva, e posteriormente com solução nutritiva diluída em $50 \%$.

As mudas foram mantidas em uma estrutura coberta com tela tipo sombrite e em seguida as plântulas obtidas foram transferidas para bancadas de desenvolvimento (berçário), e quando alcançaram de seis a oito folhas definitivas (aproximadamente 30 dias), foram transportadas para a estrutura hidropônica definitiva, onde se realizou o transplantio.

O preparo das soluções nutritivas foi realizado seguindo recomendação de Furlani et al. (1999) para suprimento de nutrientes da alface em cultivo hidropônico. As soluções hidropônicas foram preparadas a 50\% em água não salina até o dia do transplantio; nesse momento, as soluções foram preparadas a $100 \%$ e de acordo com a CE de cada tratamento salino, com início da aplicação logo em seguida ao transplantio.

Aos 7, 14 e 21 dias após transplantio (DAT) e início da salinidade, foram realizadas avaliações de trocas gasosas em três plantas por repetição, entre 8:00 e $10 \mathrm{~h}$ da manhã, utilizando-se o Infra Red Gas Analyser (IRGA) analisador de trocas gasosas modelo LCpro+. As avaliações foram realizadas em 
folhas da região mediana do caule, completamente expandidas e não sombreadas.

Foram mensuradas as seguintes variáveis: concentração interna de carbono (Ci), condutância estomática (gs), transpiração (E) e a taxa de fotossíntese líquida (A). Por meio da relação entre a taxa de fotossíntese líquida e a transpiração foi possível determinar a eficiência instantânea do uso da água (EUA) (MELO et al., 2009).

Os dados obtidos foram submetidos à análise de variância pelo teste $\mathrm{F}(\mathrm{p}<0,05)$ utilizando-se o software estatístico SISVAR (FERREIRA, 2014). Os efeitos dos diferentes níveis de salinidade foram avaliados mediante análises de regressão, enquanto o fator cultivar foi comparado pelo teste de Tukey ao nível de $5 \%$ de significância. Na ocorrência de interação entre os fatores, as curvas de regressão foram ajustadas aos níveis de condutividade elétrica da solução nutritiva separadamente para cada cultivar analisada.

\section{RESULTADOS E DISCUSSÃO}

Os resultados da análise de variância das trocas gasosas de cultivares (C) de alface crespa, cultivadas sob diferentes níveis de salinidade da solução nutritiva (NS) em sistema de cultivo hidropônico aos 7, 14 e 21 dias após transplantio (DAT) estão dispostos na Tabela 1.

Tabela 1. Resumo da análise de variância referente às variáveis condutância estomática $(g s)$, transpiração $(E)$, taxa de fotossíntese líquida $(A)$, eficiência do uso de água $(E U A)$ e concentração interna de $\mathrm{CO}_{2}(\mathrm{Ci})$ das cultivares de alface cultivadas em hidroponia aos 7, 14 e 21 dias após transplantio (DAT).

\begin{tabular}{|c|c|c|c|c|c|c|}
\hline \multirow[b]{2}{*}{$\mathrm{FV}$} & \multicolumn{6}{|c|}{ Quadrados médios } \\
\hline & GL & gs & $\mathrm{E}$ & $\mathrm{A}$ & EUA & $\mathrm{Ci}$ \\
\hline \multicolumn{7}{|c|}{7 DAT } \\
\hline NS & 3 & $0,0064^{\mathrm{ns}}$ & $9,3651 * *$ & $11,4031 * *$ & $0,1787^{\mathrm{ns}}$ & $496.70^{\mathrm{ns}}$ \\
\hline $\mathrm{C}$ & 1 & $0,0098^{\mathrm{ns}}$ & $0,6959^{\mathrm{ns}}$ & $3,0040^{\mathrm{ns}}$ & $0,7200 * *$ & $1232.38^{\mathrm{ns}}$ \\
\hline $\mathrm{NS} \times \mathrm{C}$ & 3 & $0,0013^{\mathrm{ns}}$ & $0,4359^{\mathrm{ns}}$ & $0,3560^{\mathrm{ns}}$ & $0,1495^{\mathrm{ns}}$ & $159.93^{\mathrm{ns}}$ \\
\hline Erro & 16 & 0,0042 & 0,3925 & 2,1008 & 0,0959 & 348.16 \\
\hline $\mathrm{CV}(\%)$ & & 29,04 & 14,06 & 20,36 & 18,66 & 7,48 \\
\hline \multicolumn{7}{|c|}{14 DAT } \\
\hline NS & 3 & $0,0063^{\mathrm{ns}}$ & $5,5964 * *$ & $5,4698 * *$ & $0,1358^{\mathrm{ns}}$ & $1112.19^{*}$ \\
\hline $\mathrm{C}$ & 1 & $0,0135^{*}$ & $0,0071^{\mathrm{ns}}$ & $0,0038^{\mathrm{ns}}$ & $0,0117^{\mathrm{ns}}$ & $133.81^{\mathrm{ns}}$ \\
\hline $\mathrm{NS} \times \mathrm{C}$ & 3 & $0,0032^{\mathrm{ns}}$ & $0,2936^{\mathrm{ns}}$ & $3,0003^{\mathrm{ns}}$ & $0,2477^{\mathrm{ns}}$ & $156.97^{\mathrm{ns}}$ \\
\hline Erro & 16 & 0,0025 & 0,2137 & 0,8664 & 0,0632 & 365.95 \\
\hline $\mathrm{CV}(\%)$ & & 19,21 & 12,34 & 16,94 & 16,71 & 7,23 \\
\hline \multicolumn{7}{|c|}{$21 \mathrm{DAT}$} \\
\hline NS & 3 & $0,0031^{\mathrm{ns}}$ & $4,2013 * *$ & $4,2343 * *$ & $0,9726 * *$ & $2269.65^{* *}$ \\
\hline $\mathrm{C}$ & 1 & $0,0395^{* *}$ & $6,8106 * *$ & $10,5854^{\mathrm{ns}}$ & $0,0023^{\mathrm{ns}}$ & $1344.60^{\mathrm{ns}}$ \\
\hline $\mathrm{NS} \times \mathrm{C}$ & 3 & $0,0005^{\mathrm{ns}}$ & $2,3077^{\mathrm{ns}}$ & $5,0923^{\mathrm{ns}}$ & $0,0122^{\mathrm{ns}}$ & $1229.93^{\mathrm{ns}}$ \\
\hline Erro & 16 & 0,0032 & 0,684 & 0,7901 & 0,0232 & 1699.08 \\
\hline $\mathrm{CV}(\%)$ & & 23,32 & 15,29 & 12,94 & 11,56 & 15,7 \\
\hline
\end{tabular}

*, **, ns. Significativo a 5\%, $1 \%$ pelo teste $\mathrm{F}$ e não significativo, respectivamente; FV: fontes de variação; NS: Níveis salinos; C: Cultivares; CV: Coeficiente de variação.

A condutância estomática $(g s)$ não diferiu entre nenhum dos fatores estudados aos sete DAT. No entanto, diferiu entre as cultivares aos 14 e 21 DAT, sendo a cultivar 
Alcione superior a Valentina $19,5 \%$ aos 14 DAT e inferior 38,9\% aos 21 DAT (Figura 2A, B).

A transpiração $(E)$ aos sete DAT diferiu entre os níveis de salinidade apresentando crescimento linear simultâneo à salinidade da solução nutritiva, com aumento de $98 \%$ entre a CEsn de 1,6 e 7,6 dS m${ }^{-1}$ (Figura 1D). Diferente, aos 14 e 21 DAT a $E$ decresceu com o aumento da salinidade, com reduções de 48 e 32,2\%, respectivamente entre a condutividade elétrica da solução nutritiva (CEsn) de 1,6 e 7,6 dS m${ }^{-1}$ (Figura 1E, F).
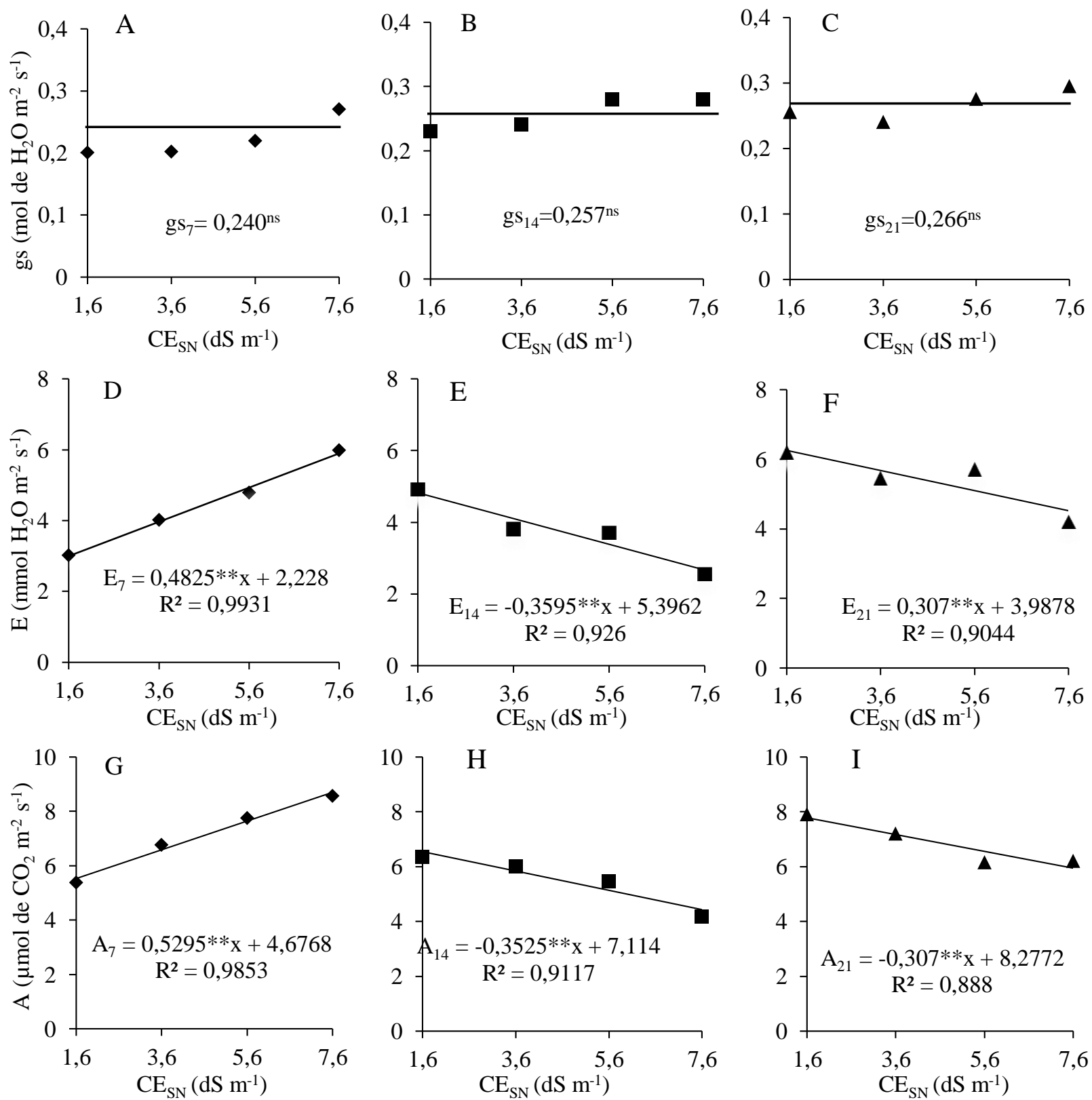

Figura 1. Condutância estomática - $g s(\mathrm{~A}, \mathrm{~B}$ e C), transpiração - $E(\mathrm{D}, \mathrm{E}$ e F) e taxa de fotossíntese líquida - $A(\mathrm{G}, \mathrm{H}$ e I) em cultivares de alface cultivada em sistema hidropônico com solução nutritiva de diferentes salinidades, aos 7, 14 e 21 dias após o transplantio (DAT). $=7$ DAT, $\mathbf{\square}=14$ DAT e $\boldsymbol{\Delta}=21$ DAT. Os dados de condutância estomática foram transformados por $\mathrm{x}^{2}$.

Assim como a $E$ aos sete DAT, a fotossíntese líquida $(A)$ também aumentou com o acréscimo da salinidade da solução nutritiva de 1,6 para 7,6 $\mathrm{dS} \mathrm{m}^{-1}$, com incremento de $59,6 \%$ entre a menor e a maior CEsn (Figura 1G). Enquanto isso, aos 14 e 21 
DAT a $A$ diminuiu com o aumento da salinidade, com reduções de 34 e $21,5 \%$,
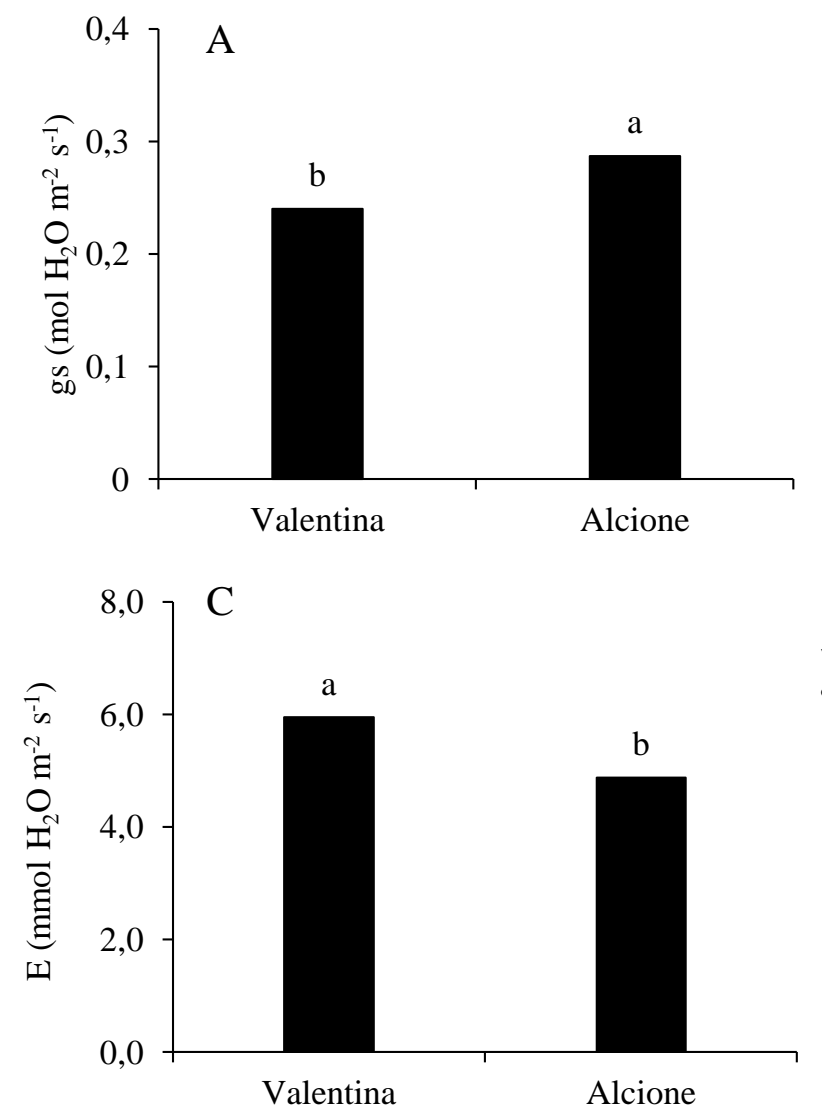

respectivamente entre a CEsn de 1,6 e 7,6 dS $\mathrm{m}^{-1}$ (Figura $\left.1 \mathrm{H}, \mathrm{I}\right)$.
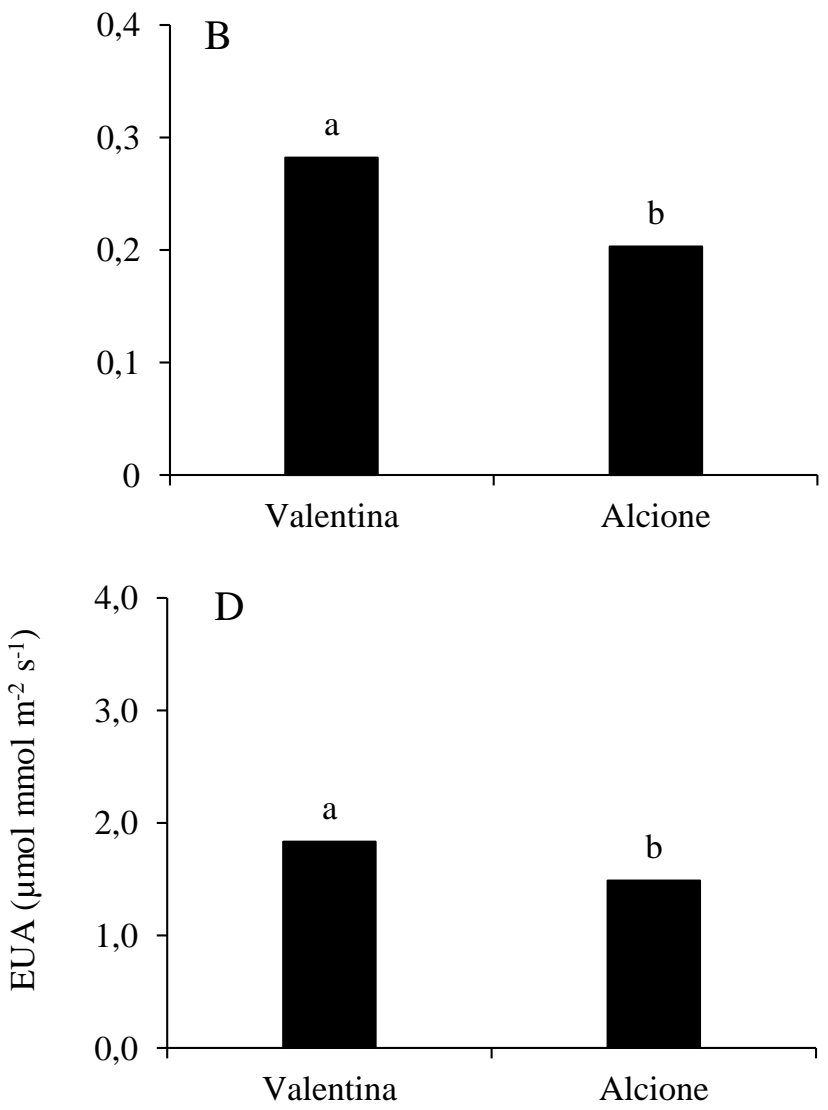

Figura 2. (A e B) Condutância estomática - $g s$ aos 14 e 21 dias após o transplantio - DAT; (C) transpiração - $E$ aos 21 DAT; e (D) eficiência no uso da água - EUA aos 7 DAT em cultivares de alface crespa em sistema hipdropônico.

Pode-se deduzir então, que aos sete DAT as variáveis de trocas gasosas $E$ e $A$ não foram afetadas negativamente pela salinidade, provavelmente por ter ocorrido um processo de percepção do estresse e, consequente aclimatação de curto prazo que a cultura realizou como mecanismo de adaptação. Assim, as plantas com o aumento da salinidade nos primeiros sete dias de estresse aumentaram a taxa de transpiração, na tentativa de excluir o excesso de íons tóxicos dos tecidos foliares através da corrente transpiratória (MUNNS; TESTER, 2008).

Quanto ao aumento da taxa fotossintética em condições de salinidade pode estar relacionado segundo Sá (2014), ao aumento na produção de fotoassimilados visando evadir-se das condições de estresse impostas pelo meio salino ou garantir a sobrevivência caso o estresse seja prolongado.

Por outro lado, o decréscimo de $E$ e $A$ a partir dos 14 DAT, possivelmente se deve ao fato de que a alface com o passar dos dias passou a sofrer estresse em decorrência do tempo de exposição à solução nutritiva salina. Desse modo, diminuindo a transpiração em decorrência do estresse hídrico induzido, ocasionado pelo efeito osmótico, com consequente redução da taxa fotossintética. Resultados semelhantes foram apontados por Bosco et al. (2009) em estudo com a cultura da berinjela cultivada hidroponicamente sob diferentes níveis salinos, os quais também constataram que a solução nutritiva com CEsn de $14,1 \mathrm{dS} \mathrm{m}^{-1}$ causou reduções nas taxas de assimilação líquida de $\mathrm{CO}_{2}$ e transpiração. 
Embora a diminuição da taxa fotossintética esteja comumente associada à condutância estomática foliar em plantas submetidas a condições de salinidade (SILVA et al., 2010), no presente estudo não se pode atribuir este declínio apenas a esta condição já que $g s$ não foi afetada pela salinidade; logo pode-se considerar que esta reação pode ter ocorrido devido a limitações de origem não estomática, que para Lawlor (1995) podem estar relacionadas com possíveis danos fotoquímicos (fotoinibição e/ou fotoxidação) ou aos danos no aparato de fixação bioquímica do carbono.

Adicionalmente, os resultados desse estudo corroboram com os de Tatagiba et al. (2014), os quais sugerem que a diminuição da assimilação de $\mathrm{CO}_{2}$, da condutância estomática e da transpiração das plantas pode ser provocada pelo excesso de íons. Em plantas de citros, sob cultivo hidropônico com água salina foi observado que os efeitos primários da salinidade estavam relacionados à diminuição da condutância estomática, levando à redução da difusão de $\mathrm{CO}_{2}$ e, consequentemente, da taxa de fotossíntese líquida (SILVA et al., 2014).

A eficiência do uso de água $(E U A)$ aos 7 e 14 DAT, embora não tenha sido afetada pela salinidade da solução nutritiva, decresceu $22,2 \%$ em função do incremento da mesma aos sete dias (Figura 3A), e aumentou 21,2\% entre as CEsn de 1,6 a 7,6 $\mathrm{dS} \mathrm{m}^{-1}$ aos 14 dias (Figura 3B). Ainda, aos sete DAT, a cultivar Valentina teve a EUA superior $27 \%$ a Alcione, independente da salinidade (Figura 2D). Enquanto isso aos 21 DAT a EUA seguiu o comportamento da $E$ e $A$, chegando a reduzir $46,2 \%$ entre a CEsn de 1,6 e $7,6 \mathrm{dS} \mathrm{m}^{-1}$ (Figura 3C).
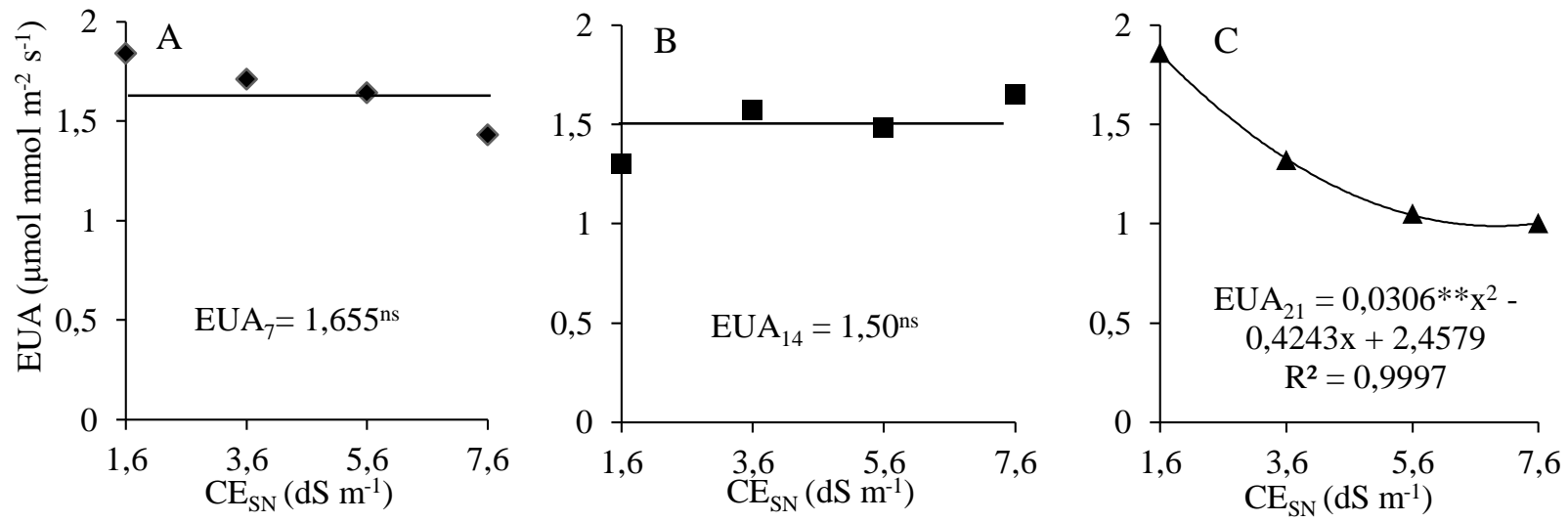

Figura 3. Eficiência do uso da água - EUA (A, B e C) em cultivares de alface cultivada em sistema hidropônico com solução nutritiva de diferentes salinidades, aos 7, 14 e 21 dias após o transplantio $(\mathrm{DAT})$.

O decréscimo da EUA aos sete dias pode ser devido ao consumo de água pelas plantas irrigadas com solução mais concentrada quando comparado com o tratamento de menor salinidade. Este efeito pode estar relacionado com a diminuição do potencial total da água, devido à alta concentração de sais solúveis e a maior transpiração das plantas no início do estresse. Além disso, a absorção de água pela planta que ocorre através de um processo passivo, mas que depende do gradiente de potencial de água $(\Delta \Psi \mathrm{w})$; diferentes CEsn reduzem a energia livre da água e, conseqüentemente, o gradiente de potencial da água (TAIZ; ZEIGER, 2013), o que pode causar uma redução na $E U A$ pelas plantas nestas condições.

Haja vista que a EUA reflete a relação entre a transpiração e a assimilação de $\mathrm{CO}_{2}$, para Taiz e Zaiger (2013) a interdependência expressa por essa relação está associada à quantidade de carbono que a planta fixa por cada unidade de água que se perde no processo (JAIMEZ et al., 2005), sendo desejável, portanto, a absorção do máximo de $\mathrm{CO}_{2}$ com o mínimo de perda de água. Neste sentido, os decréscimos observados na EUA são reflexos dos aumentos encontrados na taxa 
de assimilação de $\mathrm{CO}_{2}$ e, sobretudo na transpiração das plantas de alface.

Ressalta-se, ainda, que durante as trocas gasosas a absorção de dióxido de carbono do meio externo, via estomática, resulta também em perda de água, e que para diminuir essa perda a planta restringe a entrada de $\mathrm{CO}_{2}$, resultando também numa diminuição da taxa fotossintética e, consequentemente, aumenta a EUA (SHIMAZAKI et al., 2007).

Para a concentração interna de $\mathrm{CO}_{2}(\mathrm{Ci})$ aos sete DAT, não se constatou diferença significativa entre os fatores estudados (NS) e (C), nem da interação entre eles. No entanto, nota-se uma redução média percentual de 3,28\% entre a CEsn de $1,6 \mathrm{dS} \mathrm{m}^{-1}$ e 7,6 $\mathrm{dS} \mathrm{m}^{-1}$ (Figura 4A). Já aos 14 DAT observou-se que $\mathrm{Ci}$ aumentou em função do incremento salino da solução nutritiva, chegando a $10,3 \%$ entre a

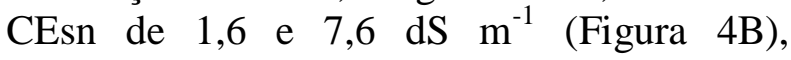
enquanto aos 21 DAT o maior Ci $(290,55$ $\mu \mathrm{mol} \mathrm{m} \mathrm{m}^{-2} \mathrm{~s}^{-1}$ ) foi estimado na CEsn de $5,6 \mathrm{dS}$ $\mathrm{m}^{-1}$, decrescendo a partir desta até 7,6 $\mathrm{dS} \mathrm{m} \mathrm{m}^{-1}$ (Figura 4C).
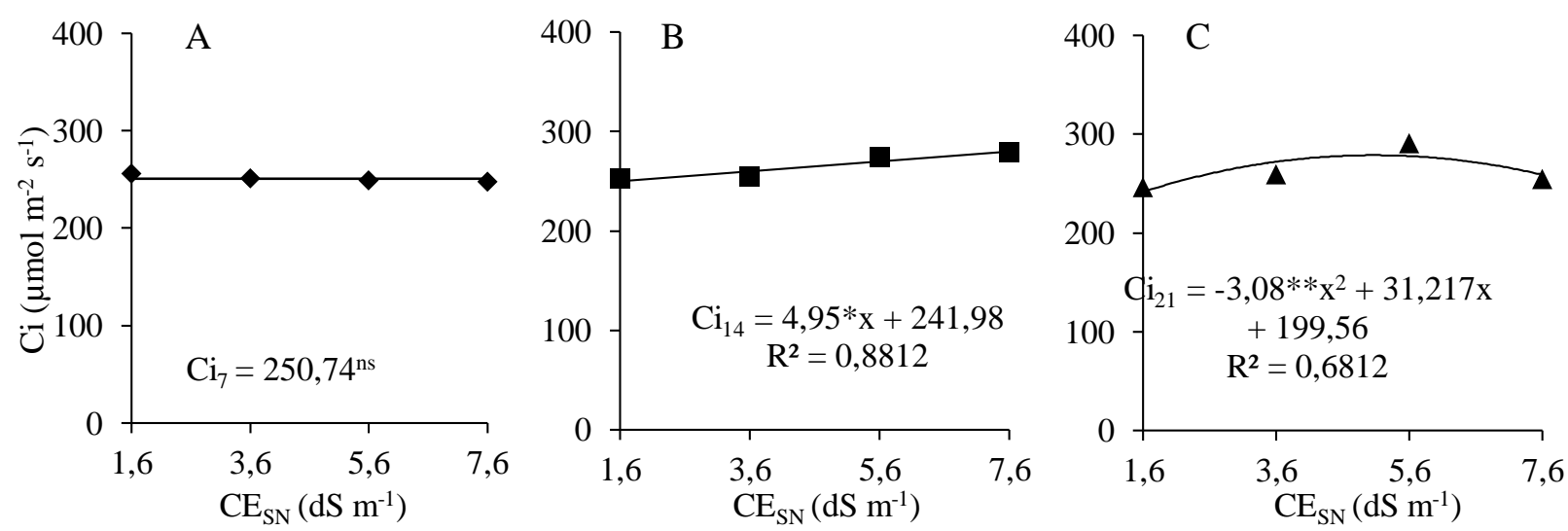

Figura 4. Concentração interna de carbono - Ci (A, B e C) em cultivares de alface cultivada em sistema hidropônico com solução nutritiva de diferentes salinidades, aos 7, 14 e 21 dias após o transplantio (DAT). $\bullet 7$ DAT, $\boldsymbol{\square}=14$ DAT e $\boldsymbol{\Delta}=21$ DAT.

Desta forma, pode-se inferir que embora tenha ocorrido um decréscimo de $\mathrm{Ci}$, este não afetou a disponibilidade de substrato para a fotossíntese provocando restrição da atividade fotossintética, pois segundo Farquhar e Sharkey (1982), durante as trocas gasosas os estômatos regulam a concentração interna de $\mathrm{CO}_{2}$ na planta, no entanto, esse pode se acumular na câmara subestomática, caso o estresse se torne severo.

Nesse sentido, as maiores concentrações internas de $\mathrm{CO}_{2}$ e a redução da atividade fotossintética, constatada no presente trabalho, podem indicar baixa atividade da enzima ribulose-1,5-bisfosfato carboxilase-oxigenase ( $\mathrm{RuBisCO})$ tendo em vista que esta enzima é responsável pela redução do carbono (SILVA et al., 2014) através do processo de carboxilação primária do ciclo de CalvinBenson (WALTER et al., 2015). Tal situação ainda pode ser atribuída a algum fator não estomático, como a disponibilidade de adenosina trifosfato (ATP) e de nicotinamida adenina dinucleótido fosfato (NADPH), provenientes da cadeia transportadora de elétrons do fotossistema II (SILVA et al., 2014).

Em relação ao aumento do $\mathrm{Ci}$ aos 14 DAT, provavelmente, indica que o $\mathrm{CO}_{2}$ não está sendo utilizado eficientemente para a síntese de açúcares pelo processo fotossintético (SILVA et al., 2014), fato comprovado pela depleção na taxa de fotossíntese líquida a partir dos 14 DAT, quando o $\mathrm{Ci}$ começou a aumentar.

Poucos relatos são encontrados na literatura referentes às trocas gasosas da cultura da alface em condições salinas, no entanto, estudos com alface sob estresse hídrico e doses de fósforo apontam que houve aumento da fotossíntese e da eficiência no uso da água nas plantas estressadas com o 
aumento das doses de fósforo, indicando que esse nutriente melhora as trocas gasosas de alface em condição de estresse (FÁTIMA et al., 2018). Nesse estudo, possivelmente, no início do estresse as plantas tiveram melhor absorção e aproveitamento dos nutrientes ofertados e, assim, tiveram melhor aclimatação fisiológica ao estresse salino.

Aos 14 e 21 DAT, possivelmente, a taxa fotossintética e a transpiração reduziram em decorrência da exposição prolongada da alface a elevada concentração de sais da solução nutritiva, que pode ocasionar segundo Munns e Tester (2008) toxicidade iônica, levando a alterações em uma grande variedade de reações metabólicas, pois quando grandes concentrações de íons se acumulam nos tecidos, além de afetar negativamente a atividade fotoquímica (SILVA et al., 2010) ainda provocam distúrbios fisiológicos e redução da fotossíntese (SOUZA et al., 2011).

Essas reduções parciais das trocas gasosas das plantas de alface com o aumento da salinidade, provavelmente é o que reflete nas reduções da massa fresca foliar sem causar injúrias visuais e alterar a qualidade do produto, como encontrado por Guimarães et al. (2017). Contudo, além da compreensão das trocas gasosas, pesquisas futuras também devem avaliar as características qualitativas para melhor compreensão da relação entre as trocas gasosas, a produção de massa fresca e a sua qualidade, quando as plantas de alface são cultivadas sob salinidade em sistema hidropônico.

\section{CONCLUSÕES}

As cultivares de alface Valentina e Alcione desempenharam mecanismos fisiológicos de adaptação ao estresse salino durante os sete primeiros dias de exposição aos tratamentos em cultivo hidropônico.

A partir dos 14 dias após o transplantio, a transpiração e a taxa de fotossíntese líquida decrescem linearmente a partir da condutividade elétrica da solução nutritiva de $1,6 \mathrm{dS} \mathrm{m}^{-1}$, enquanto a condutância estomática não é afetada pela salinidade.
A eficiência no uso da água reduz com o aumento do estresse salino e do tempo de exposição em cultivares de alface crespa, enquanto a concentração interna de carbono aumenta.

\section{REFERÊNCIAS BIBLIOGRÁFICAS}

AYERS, R. S.; WESTCOT, D. W. Qualidade da água na agricultura. Estudos FAO: Irrigação e Drenagem, 29. Campina Grande, Brasil. 1999, 153 p.

BOSCO, M. R. O.; OLIVEIRA, A. B.; HERNANDEZ, F. F. F.; LACERDA, C. F. Efeito do $\mathrm{NaCl}$ sobre o crescimento, fotossíntese e relações hídricas de plantas de berinjela. Revista Ceres, v. 56, n. 3, p. 296302, 2009.

BLISKA, A.; HONORIO, S. L. Cartilha tecnológica de hidroponia. Campinas: Unicamp. 1996, 51p.

BRITO, L. T.; PEREIRA, L. A.; MELO, R. F. Disponibilidade hídrica subterrânea. Agência Embrapa de Informação Tecnológica, 2016.

DIAS, N. S.; BLANCO, F. F. Efeito dos sais no solo e na planta. In: GHEYI, H. R; DIAS, N. S.; LACERDA, C. F. (Eds). Manejo da salinidade na agricultura: estudos básicos e aplicados. Fortaleza, INCT Sal, 2010, 472 p.

ECHER, R.; LOVATTO, P. B.; TRECHA, C. O.; SCHIEDECK, G. Alface à mesa: implicações socioeconômicas e ambientais da semente ao prato. Revista Thema, v. 13, n. 3, 2016.

FARQUHAR, G. D.; SHARKEY, T. D. Stomatal conductance and photosynthesis. Annual review of plant physiology, v. 33, n. 1, p. 317-345, 1982.

FÁTIMA, R. T.; JESUS, E. G.; GUERRERO, A. C.; ROCHA, J. L. A.; BRITO, M. E. B. Crescimento e trocas gasosas em alface cultivada sob regimes hídricos e adubação 
fosfatada. Revista Brasileira de Agricultura

Irrigada, v. 12, n. 3, p. 2683-2691, 2018. DOI: $10.7127 /$ rbai.v12n300854

FERREIRA, D. F. Sisvar: A Guide for its Bootstrap procedures in multiple comparisons. Ciência e Agrotecnologia, v. 38, n. 2, 109112, 2014. https://doi.org/10.1590/S141370542014000200001

FURLANI, P. R.; SILVEIRA, L. C. P.; BOLONHEZI, D.; FAQUIN, V. Cultivo hidropônico de plantas. Campinas: Instituto Agronômico. Boletim técnico, 180. 1999, 52p.

GUIMARÃES, R. F. B.; NASCIMENTO, R.; RAMOS, J. G.; LIMA, S. C.; CARDOSO, J. A. F.; MELO, D. F. Acúmulo de fitomassa de cultivares de alface hidropônica submetidas à salinidade. Revista Brasileira de Agricultura Irrigada, v.11, n. 8, p. 214-2151, 2017.

JAIMEZ, R. E.; RADA， F.; GARCÍANÚÑEZ, C.; AZÓCAR, A. Seasonal variations in leaf gas exchange of plantain cv. Hartón (Musa AAB) under different soil water conditions in a humid tropical region. Scientia Horticulturae, v. 104, n. 1, p. 79-89, 2005.

LAWLOR, D. W. Fotossíntese, produtividade e meio ambiente. Journal of Experimental Botany, v. 4, n. 1, p. 1449-1461, 1995.

MELO, A. S.; SILVA JÚNIOR, C. D.; FERNANDES, P. D., SOBRAL, L. F.; BRITO, M. E. B.; PAULA, J. D. M. D. D. Alterações das características fisiológicas da bananeira sob condições de fertirrigação. Ciência Rural, v.39, n.3, p.733-741, 2009.

MUNNS, R.; TESTER, M. Mechanisms of salinity tolerance. Annual Review of Plant Biology, v.59, p. 651-681, 2008.

PAULUS, D.; DOURADO NETO, D.; FRIZZONE, J. A.; SOARES, T. M. Produção e indicadores fisiológicos de alface sob hidroponia com água salina. Horticultura Brasileira, v.28, n.1, p.29-35, 2010.
http://dx.doi.org/10.1590/S010205362010000100006

PAULUS, D.; PAULUS, E.; NAVA, G. A.; MOURA, C. A. Crescimento, consumo hídrico e composição mineral de alface cultivada em hidroponia com águas salinas. Revista Ceres, v. 59, n. 1, p. 110-117, 2012.

SÁ, F.V. S. Fisiologia de porta-enxertos de citros sob água salina em cultivo hidropônico. 2014. 55 f. Monografia (Graduação em Agronomia). Universidade Federal de Campina Grande. Pombal, Brasil.

SALA, F. C.; COSTA, C. P. Retrospective and trends of Brazilian lettuce crop. Horticultura brasileira, v. 30 , n. 2, p. 187194, 2012.

SHIMAZAKI, K. I.; DOI, M.; ASSMANN, S. M.; KINOSHITA, T. Light regulation of stomatal movement. Annual Review of Plant Biology, v. 58, n. 1, 219-247, 2007.

SILVA, E. N.; RIBEIRO, R. V.; FERREIRASILVA, S. L.; VIÉGAS, R. A.; SILVEIRA, J. A. G. Comparative effects of salinity and water stress on photosynthesis, water relations and growth of Jatropha curcas plants. Journal of Arid Environments, v.74, p.1130-1137, 2010.

SILVA, L. A; BRITO, M. E.; DA S, S.; FRANCISCO, V.; MOREIRA, R. C.; SOARES FILHO, W. D. S.; FERNANDES, P. D. Mecanismos fisiológicos em híbridos de citros sob estresse salino em cultivo hidropônico. Revista Brasileira de Engenharia Agrícola e Ambiental, v. 18, suplemento, 2014 http://dx.doi.org/10.1590/18071929/agriambi.v18nsupps1-s7

SILVA, M. G.; OLIVEIRA, I. S.; SOARES, T. M.; GHEYI, H. R.; SANTANA, G. O.; PINHO, J. S. Growth, production and water consumption of coriander in hydroponic system using brackish waters. Revista 
Brasileira de Engenharia Agrícola e Ambiental, v.22, n.8, p.547-552, 2018. http://dx.doi.org/10.1590/18071929/agriambi.v22n8p547-552

SOUZA, R. P.; MACHADO, E. C.; SILVEIRA, J. A. G.; RIBEIRO, R. V. Fotossíntese e acúmulo de solutos em feijoeiro caupi submetido à salinidade. Pesquisa Agropecuária Brasileira, v. 46, n. 6, p. 587592, 2011. http://dx.doi.org/10.1590/S0100204X2011000600003

TAIZ, L.; ZEIGER, E. Fisiologia vegetal. 5. ed. Artmed, Porto Alegre, Brasil. 2013, 918 p.

TATAGIBA, S. D.; MORAES, G. A. B. K.; NASCIMENTO, K. J. T.; FIGUEIREDO PELOSO, A. Limitações fotossintéticas em folhas de plantas de tomateiro submetidas a crescentes concentrações salinas. Revista Engenharia na Agricultura, v. 22, n 2, p. 138-149, 2014. http://www.locus.ufv.br/handle/123456789/15 745

WALTER, L. C.; ROSA, H. T.; STRECK, N. A. Mecanismos de aclimatação das plantas à elevada concentração de $\mathrm{CO}_{2}$. Ciência Rural, v. 45, n. 9, p. 1564-1571, 2015. 